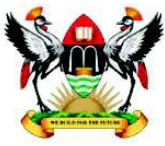

East African School of

Higher Education Studies \& Development
Makerere Journal of Higher Education

ISSN: $1816-6822 ; 8$ (1) (2016) 3 - 24

DOI: http://dx.doi.org/10.4314/majohe.v8i1.1

(C) The Author(s) 2016

Reprints \& permission: EASHESD

http://ajol.info/majohe

\title{
Implications of Teacher Educators' Practices in Assessment for Student Learning in Tanzania
}

\author{
Philipo Lonati Sanga ${ }^{1}$ \\ ${ }^{1}$ School of Education, University of Dar es Salaam, Tanzania [E-mail: lonati_f@yahoo.com ]
}

\begin{abstract}
This study presents findings on teacher educators' practices in assessment and their implications for student learning in Tanzania. Research on classroom assessment has been dichotomizing assessment and teaching-learning processes instead of viewing assessment as an integral part of the teachinglearning process. It is against this background that this study delved into teacher educators' practices in assessment and their implications for student learning in Tanzania. Data were collected using in-depth interviews and analysed using thematic coding. The findings show that teacher educators perceive assessment as a one-shot activity in terms of tests and examinations. Consequently, teaching, learning and assessment are performed disjointedly. Despite believing that learning is an active process, teachers predominantly use deductive teaching methods, which render students passive recipients of knowledge. It is concluded that although students need to see assessment as an essential measure of their learning and as an indication of opportunities for their improvement, teacher educators are still caught in a dilemma of either facilitating students' meaningful learning or preparing students who can earn high grades.
\end{abstract}

Keywords: Teacher education; Assessment for learning; Innovation.

\section{$1 \quad$ Introduction}

An education process in the classroom ought to involve at least three core processes: teaching, learning and assessment. These processes should be constructively aligned in such a way that change in one compels a sympathetic adjustment of the rest (Stiggins, 2007). A problem arises when teachers and educators do not possess the knowledge and skills required to balance the three processes. The fundamental reason for students' lack of meaningful learning and acquisition of skills deemed imperative for survival in this knowledge economy is the consistent detachment, or at least poor connection, of these 
three processes. Effective assessment helps to improve student learning and informs the teachers of their teaching process. Therefore, in order for teachers to maximize the potential benefits of assessment to inform teaching and improve learning, the three processes must be planned and carried out concurrently.

Several scholars have emphasized the necessity of designing and executing assessments that have the potential of measuring students' intellectual accomplishments that are worthwhile, significant and meaningful (DarlingHammond \& Snyder, 2000; Gibbs \& Simpson, 2004; Griffin \& Hett, 2004, Stiggins, 2007). Such assessments should equip students with the capacity to demonstrate meaningful application of essential knowledge, skills and values to real-world situations, beyond the school (Griffin \& Hett, 2004; Mueller, 2005). What counts for success in schools is often considered trivial, less relevant and contrived. The quality and utility of assessment rests upon the extent to which the performance measured represents appropriate and meaningful forms of human achievements that are relevant in real-life situations.

In Tanzania, like its East African counterparts, university graduates, including student teachers, are persistently blamed for graduating 'successfully' but failing to effectively discharge their anticipated real-life responsibilities (Kajoro, Chirure \& Simiyu, 2013). This phenomenon observably brings to the fore questions about how students are being taught, how they learn, and how they are being assessed (Darling-Hammond \& Snyder, 2000; Shepard, 2000; Stiggins, 2007). Many secondary school teachers in Tanzania and East Africa at large face challenges when preparing and implementing teaching and assessment activities for their students (for examples, see these studies: Jidamva, 2012 and Nzilano, 2013 in Tanzania; Najjumba \& Marshall, 2013 and Otaala, Maani \& Bakaira, 2013 in Uganda). Serious shortfalls have been identified in areas such as the way these teachers were trained at college, especially the assessment processes that they underwent. In most cases only abstract learning outcomes and their application in limited contexts as measured by paper and pencil tests and academic assignments such as writing term papers are assessed. Assessment of student learning ought to consist of a wide range of student attributes and abilities, including cognitive, psychomotor and affective domains, which determine the extent to which their learning experiences have supported their holistic development (Huba \& Freed, 2000).

Despite graduating successfully, even with excellent grades, still the motivation and quality of teachers employed in secondary schools in Tanzania has come in for criticism from several sectors (Bennel \& Mukyanuzi, 2005; Kitta \& Fussy; 2013). Such a situation, in which teachers are being employed because they hold paper qualifications but without having candid proof of the ability for quality teaching, is referred to as a "conceptual confusion" between quality and qualification (Altbach, as cited in Mosha, 2004, p. 49). It is believed 
that assessment approaches are embedded within rich pedagogical understandings and the experiences of teachers, and they reside at the core of the teaching and learning process (Darling-Hammond \& Snyder, 2000; Unwin $\&$ Caraher, 2000). It is further underlined by Gibbs \& Simpson (2004) that assessment defines what students consider to be important and how they spend their time when learning. Therefore, the need to change student learning behaviour compels a change in the methods of assessment. For that reason, this study sought to investigate the implications of teacher educators' assessment practices on student learning.

\subsection{Role of Classroom Assessment}

It has already been discussed that assessment is an integral part of the teaching and learning process, aimed at enhancing student learning and improving teaching. Stiggins (2007) asserts that assessment includes all activities carried out by teachers and learners to obtain information that can be used diagnostically to alter teaching and learning processes. It is further emphasised that, assessment directly influences any mode of learning through communicating messages about how learners should study and what things should be considered a priority in learning, as well as providing opportunities for learners on how to review, practise, and apply what they have learned, promoting learner ownership and cultivating such skills as self-regulation and self-evaluation. Assessment activities give a message to students about what they should focus on learning and how they should go about it. The message is often not explicit, and it may be given a different emphasis by teachers and by students. With this perspective, educators have the opportunity to maximise student learning through effectively designed assessment activities. Traditionally, assessment has been divided into three types: diagnostic assessment, formative assessment and summative assessment (DarlingHammond \& Snyder, 2000; Omari, 2011; Stiggins, 2007).

\subsubsection{Diagnostic Assessment}

This is usually carried out at the beginning of a topic or unit of study to assess the knowledge, interests, experiences, strengths and weaknesses of a student. Knowing students' weaknesses and strengths helps the teacher to plan for better teaching, and it can be used to clarify misconceptions before teaching depending on students' current level of knowledge. It can involve both formal and informal measurements. Diagnostic assessment tools include aptitude tests, fitness examinations, questioning, interviews, self-assessment, observation and discussing board responses. 


\subsubsection{Formative Assessment}

This is commonly undertaken on a day-to-day basis and may involve ongoing formal and informal observations throughout the course, term, semester or unit of study. It is more helpful in improving learning and modifying teaching strategies and materials because it provides feedback and information during the learning process. It involves multiple tools, such as written tests, portfolio assessments, projects, exhibitions, interviews and rating scales, reflection journals and student-teacher conferences.

\subsubsection{Summative Assessment}

This is conducted at the end of the course, topic or unit of study and helps to make judgments about student achievement at certain relevant points in the learning process. Normally it focuses on measuring the achievement of learning outcomes, which is why it takes place after the learning has been completed and provides information and feedback that sums up the teaching and learning. Examples of tools that can be used for summative assessment are tests, examinations, terms papers, projects, portfolios and performances. Summative assessment is also known as evaluation.

\subsection{Integration of Teaching, Learning and Assessment}

There is a mutual relationship between learning objectives, learning processes, teaching processes and assessment procedures (Biggs, 2003). These four variables are in a state of dynamic tension and balance in which adjustment or disturbance of one variable calls for a considerate adjustment of the other three. However, the relationships of these variables largely depend on the social, cultural and political context in which they operate. Wiggins (1993) argues that serious problems in assessment reform have to do with a "pervasive thoughtlessness about testing and failure to understand the relationship between assessment and learning" (p.3). Thoughtful teachers should realise that high quality classroom interactions that promote thinking and demonstrate learning and development lie at the heart of assessment as part of the learning and teaching processes.

When assessment is integrated with teaching and learning, both students and teachers benefit. Students are more likely to improve their learning because the teaching is focused and because they are assessed on what they are taught. Teachers are also able to focus and use their time more effectively. Because assessment involves real learning, teachers can integrate assessment into daily teaching and learning and other classroom activities. For teachers, assessment helps them not only in determining the level of students' knowledge, but also the effectiveness of the teaching process. Effective assessment helps in 
generating information that is useful in making informed decisions about the students, curriculum, institution and the general education system.

Ongoing assessment in particular that seeks to diagnose and to improve the learning, instead of merely classifying learners, is vital in learning to boost the adaptability of the systems and the personalisation of learning, increasing motivation and the quality and productivity of the learning. Assessment for learning plays an important role in determining the quality of learning due to the truth that learning activities and assessment are connected very closely in well-designed courses (Sewell, Frith \& Colvin, 2010). That is to say, higher education syllabuses have to clearly outline basic information such as learning objectives, teaching/learning methods and how assessment will be conducted and used.

The following three concepts - assessment of, for and as learning - may be worth knowing, as they expand our theoretical understanding on assessment practices in the classroom.

1. Assessment of learning is the use of student information to measure, record and report on a student's level of achievement in regards to specific learning expectations. It is normally known as summative assessment and is accompanied by number or letter grades.

2. Assessment for learning is more commonly known as formative and diagnostic assessment. In this case, student information is used to determine his/her progress in order for the teacher to adjust the classroom instruction based upon the needs of the students. Similarly, students are provided with valuable feedback on their own learning. Assessment for learning consists of initial or diagnostic assessment and formative assessment. Assessment can be based on a variety of information sources, such as teacher observation, conversation, portfolios and works in progress. Verbal or written feedback to the student is descriptive and highlights strengths, identifies challenges and points to the way forward.

3. Assessment as learning is the use of information and activities for students to further their own learning. For instance, self and peer assessments allow students to reflect on their own learning and identify areas of strength and need. These tasks offer students the chance to set their own personal goals and advocate their own learning, and it occurs throughout the learning process (Stiggins, 2007). In this mode, learning and assessment are deeply integrated such that assessment is completely part and parcel of learning.

\subsection{Teacher Preparation in Tanzania}

The United Republic of Tanzania, like many other countries, realises that quality education is the pillar of national development. It is through quality education that Tanzania can create a strong and competitive economy that can 
effectively cope with the challenges of the dynamic global economy. However, as Wagner (2010) asserts, the quality of education is dependent on the quality of teachers and the quality of teachers is the most reliable determinant of the quality of an education system.

For several decades teacher trainees in Tanzania have been selected from a pool of average-performing students who in some cases missed admission to further education in other fields. This malpractice is likely to be exacerbated by the undesirable encroachment of political leaders to education sector through their ad hoc declarations which are usually taken for granted as policies. One such typical example can be given when one of the top political officials of the ministry of education announced the government's decision to introduce a special examination for all teacher training colleges to test the academic competence of student teachers. As a matter of fact, this resolution was not backed by any empirical evidence. The top official proclaimed:

The ministry has come to learn that many of the recent graduate teachers have demonstrated poor performance in the office, prompting the government to take immediate action to reverse the trend. In the last three years we have experienced a sharp drop of teaching performance among many teachers ... so the new examination will probably help redress the matter. (Rugonzibwa, 2014, para. 4, 5)

Regrettably, such political declarations have been the basis of many educational practices within the country. The situation is worsened when student teachers meet inadequate preparations at college, coupled with poor and outdated basic facilities such as teaching and learning resources, textbooks and computer and Internet access. Besides quality teachers, adequate and modern teaching and learning facilities are necessary for effective teaching and meaningful learning. The emphasis is not only on enough numbers of teachers but also quality teachers. Focusing solely on numbers of teachers is doing more harm than good to educational sector.

One can study under the tree; if the teachers are available, things will go on.

One can lack textbooks but with the presence of enough numbers of teachers, one can keep on studying and will eventually pass the exam. Some of us went to school and were studying under the trees, yet we passed exams, and could not feel the problems. The presence of teachers necessarily made it possible for the students to pass the exam. (King, 2013, p. 54).

With this understanding, one may question the legitimacy of claims from some authors that when "enough numbers of teachers" (King, 2013, p.54) are present things can go on even with poor teaching and learning resources. Such unfounded statements are not only misleading but also detrimental to educational sector, especially when heard from socially or politically influential individuals. 


\subsection{Teacher Certification and Employment}

Subsequent to liberalisation policies established in 1994 (MOEVT, 2007), the Tanzanian government encouraged the private sector to engage in education provision services in order to complement the government's efforts. Many private colleges of education have been established since then. In Tanzania, teacher education and training is categorized into in-service (INSET) and preservice (PRESET) programs. In-service training focuses on training teachers who are already working. This is done as part of professional development and/or personal growth efforts in the profession. It can be provided both as a long-term or short-term education and training programme, and its core purpose is to improve the knowledge, skills and professional attitude of teachers for the better discharging of their teaching responsibilities. Pre-service training deals with the preparation of students who aspire to become teachers by profession. The training enables future teachers to be exposed to the foundations of education (philosophy), educational psychology, pedagogy and professional ethics in education. Likewise, prospective teachers are being facilitated in developing a mastery of their teaching subjects, such as mathematics, geography and chemistry.

The structure of teacher preparation in Tanzania is currently undergoing a major overhaul in which, among others, the certificate and diploma holding teachers are being phased out to give room for any teacher to possess at least a bachelor's degree. A noteworthy point is that, in Tanzania, the certification undertaken by the education institution is a sufficient endorsement for a student teacher to be employed in either public or private schools. However, some private schools may wish to conduct an interview prior to finally employing their teachers.

\section{$2 \quad$ Related Literature}

In Spain, Remesal (2011) explored in-service teachers' views on the functions of assessment in basic schooling as a necessary first-step before challenging teachers' practices towards formative assessment.

Two phases of semi-structured interviews were undertaken for 50 primary and secondary school teachers (an average of 22 years of teaching experience). Analysis of interview transcripts suggested that teachers' conceptions about the functions of assessment fall under four distinct categories: pedagogical, societal, mixed-pedagogical, and mixed-societal. However, extracting data from 50 participants through interviews should normally bring rich data (Onwuegbuzie \& Collins, 2007). Further, her lack of triangulation and 
depending solely on one source of data collection may cast some doubts over the reliability and validity of the study.

Thomas (2012) conducted a cross-sectional survey to compare the beliefs of trained and untrained middle and secondary school teachers in Pakistan about classroom assessment. This study administered a survey questionnaire to 88 trained and 35 untrained teachers selected from 15 different schools. The major findings indicated no significant difference between the beliefs of trained and untrained teachers regarding classroom assessments and their selection of assessment strategies. Thomas concludes that, for reasons such as time constraints, some teachers, especially trained teachers, are reluctant to use some student-centred strategies. This reluctance to use alternative assessment strategies is due to factors related to energy and financial costs, time constraints and subjectivity of marking. This study, however, could do more justice by corroborating the data collection with any other instrument instead of depending entirely on a survey questionnaire.

In Tanzania, not many studies related to teacher preparation programs have been conducted. Even the few available studies have focused on aspects other than assessment. For instance, Msonde (2011) employed a combination of case study and phenomenological approaches to investigate how the learning study guided by the variation theory can enhance teachers' competencies using the learner-centred approach (LCA) in Tanzanian secondary schools. Data collection was done using interview protocols, lesson video recordings, lesson preparatory meetings, teacher's journals and students' tests. It was found that, teachers' capability to implement LCA improved gradually in slightly different ways, which in turn improved student learning. Nevertheless, one wonders whether teachers' understanding and application of LCA in teaching tend to be reflected in their assessment practices or not.

More recently, Nzilano (2013) examined the ways pre-service teachers prepared for classroom teaching and assessment of learning activities. $\mathrm{He}$ employed questionnaires, semi-structured interviews, portfolio reviews and classroom observations to collect data. One serious area of incompetence he identified is their assessment skills. Some were not able to set assessment tools that reflected the student learning outcomes (Nzilano, 2013), and others suggested they did not have enough time to plan assessment and construct high quality assessment tools. Mtitu (2014) undertook a study that is similar to that conducted by Msonde (2011). For his part, Mtitu focused on exploring learnercentred teaching (LCT) in Tanzania from the perceptions and experiences of secondary school geography teachers. Semi-structured interviews, classroom observations and detailed reviews of teachers' own teaching portfolios were used as primary sources of data. Besides his findings, there is still a lingering desire to know how well teachers connect their knowledge and practices of LCT with their classroom assessment practices. 
This is a multiple case study that draws qualitative data from eight in-depth interviewed teacher educators from two different universities-one public and the other private. The interview data are complemented with data from literature analysis and self-administered questionnaires. A good case "provides an opportunity for knowledge to be linked to the context, theories linked to practice, and abstractions linked to concrete experiences." (Chung, 1997, p.1). Eight teacher educators were purposively selected among those who are directly and actively involved in preparing student teachers (prospective secondary school teachers, college tutors and educators) at university. Their experiences as teacher educators ranged from five to forty years. Data from the in-depth interviews was analysed by reducing them into themes and sub-themes (Miles \& Huberman, 1994). Firstly, data were processed by clustering together similar topics, then sorting out major topics, unique topics and "leftovers" (Creswell, 2009, p. 186). I focused on research objectives and questions as Miles \& Huberman (1994) precisely underline that the purpose of the study is your storyline and it is the analytic thread that unites and integrates the major themes of your transcriptions. The seven-stage analytic processes suggested by Creswell (2009) and significantly informed by the grounded theory method were applied. The coding process was enhanced by MAXQDA software, which greatly helped in systematically organizing and evaluating the transcripts (Schönfelder, 2011).

\section{$4 \quad$ Findings}

Learning is an active process where the learner constructs new knowledge by discovering principles themselves under the facilitation of a teacher (see Bruner, 1986; Vygotsky, 1987). For teachers to be able to understand their teaching and be capable of facilitating learning, they need to be critical about their students' learning and their teaching and assessment roles. While only three out of the eight teacher educators consider learning to be a product that culminates in students passively receiving material from the teacher, the other five described it as a process that involves the active interaction between a teacher and learners to produce knowledge. When learning is viewed as a product, the same performance measure applies to all students, and learning facilitation can be reduced to lecturing because the same pieces of information and instruction are seen as sufficient for all students. On the contrary, when regarding learning as a process then more emphasis is placed on the differentiation and individualisation of teaching activities. Assessment focuses 
more on comparing one's own achievement (criterion referenced assessment) for the purpose of improvement as opposed to the norm-referenced assessment emphasized in learning as a product.

In learning as an active process, the teacher struggles to create a learning atmosphere in which the student can learn to reorganize the new information and their prior knowledge into new knowledge about the content and to apply it. This is what Vygotsky (1987) call constructive learning. In support of this idea, two teacher educators expressed a similar idea.

To me, learning is a process and a product in which students actively engage in receiving, organizing and re-organizing materials from the teacher. (Transcript T4, June 19, 2015).

Learning should be confirmed through students' ability to perform in reallife situations what they have learnt. For example, if you are teaching a subject which is more or less of doing (hands-on activities) then learning refers to how they perform in reality what you've taught them in the classroom. (Transcript T2, June17, 2015).

These two teacher educators conceptualised learning as a product manifested by the change of some behaviour because, according to their explanations, it requires conscious planning to be undertaken by the teacher on what should be taught and learnt. The teacher therefore works hard to achieve his/her predetermined objectives in an uninterrupted manner. In harmony with these words, one teacher educator contended that at university level we have lecturers whose work is to lecture. In his view, there is no time for questions, asking if students understand and for explaining issues in lectures.

If I'm going to the lecture I write everything exactly that I will speak in that lecture (showing a bunch of hand-written sample notes that he normally uses) so that I don't waste time explaining things. In one lecture you have to cover so much material. (Transcript T6, August 27, 2015)

By and large, it has been established that most teacher educators consider learning to be an active process through which a teacher interacts with students to organize and reorganize information to produce knowledge. When perceived this way, the emphasis of assessment tends to criterion-referenced assessment so as to see areas that require improvement. By emphasizing the processing of information to produce knowledge through the interaction of teacher and students, this conception concurs with both the cognitive (Bruner, 1986) and social (Vygotsky, 1987) learning orientations.

The minority of teacher educators who considered learning as a passive reception of material from the teacher and manifested by the students' performance in a test or examination are characteristically largely influenced by 
the behaviourist learning orientation. Behaviourist teachers can be identified through their systematic design of instruction, behavioural and performance objectives, competency-based instruction, and teacher accountability. Therefore, their emphasis is norm-referenced assessment that triggers competition among students.

It is, however, surprising to notice that even those teacher educators who conceptualized learning as an active process could not show any significant differences in terms of their teaching and assessment methods when compared to their counterparts who regarded learning as a product. In either case, the traditional teaching and assessment methods constituted their dominant practices.

\subsection{Role of Assessment for Student Learning}

In relation to the role of assessment, responses from the eight teacher educators emphasised the following: Assessment is used for certification and promotion; assessment is needed for diagnosing student needs, problems, weaknesses and strengths; assessment helps institutions to put more strategies on teaching and learning depending on assessment results, especially when certain trends of results consistently happen unusually; and assessment shows the extent to which students have understood the taught materials. Understanding the broader roles of assessment may require teachers to not only depend on their experiences, but to be flexible in order to add new knowledge through attending relevant training programs.

Assessment is very important, there is no way you can be able to tell that students have understood you, acquired some knowledge or skills without assessing them. (Transcript T1, June 16, 2015)

In order to achieve reliable results from assessment of students, teachers need to involve students in the planning of assessment activities, and students have to be given explicit guidelines on how to undertake the activities. Equally important, the marking should be fair enough that the grades reflect the students' quality of work as much as possible. Quality work ought to be significantly creative but also meet the predetermined standards. Assessment is necessary because without it there is no way a teacher can tell that students have understood and acquired some values, knowledge or skills. Assessment is not a one-shot activity; it is a way of discovering student difficulties in understanding certain parts of the lessons in a progressive manner. Even if there are no problematic areas for students, assessment will still help the teacher to evaluate the materials and teaching methods. As a teacher, you may need to review how better you are performing in the class to attain lesson objectives. As much as possible, effective assessment needs to promote teacher-learner and 
learner-learner interaction (Puspitasari, 2008; Simonson, Smaldino \& Albright, 2006).

If teachers focus on assessment for learning then it becomes easy for them to explore better ways of facilitating student learning. Assessment for learning helps the teacher not only to understand the teaching and learning process, but also to be able to facilitate learning more meaningfully. It informs the teacher of what students are able or not able to do. For example, when certain students fail to perform their assignments the teacher may then decide to review his/her teaching approaches or change the resources for teaching. When put together, this study comes to the conclusion that the analysis of the responses of all eight teacher educators indicates that they had been talking about three basic roles of assessment (the tripartite role of assessment): the feedback role, the certification role and the feed forward role as synthesized and summarized in Figure 1.

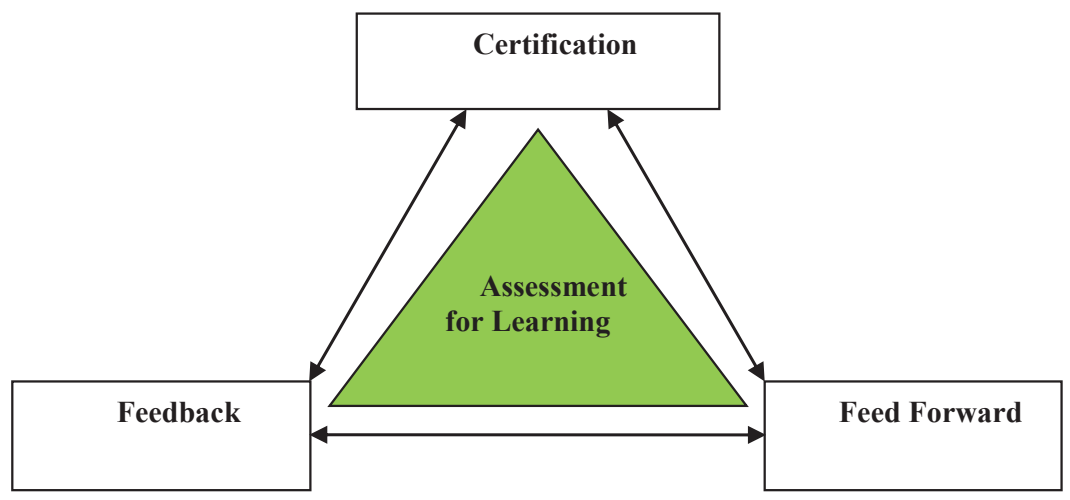

Figure 1. The tripartite role of assessment for learning

From Figure 1, the certification role of assessment is done when grading is meant for purposes such as promotion from one level to another and transition to a new level of school. While summative assessment is normally associated with certification, in practice, diagnostic assessment can also serve this purpose. The feedback role of assessment is expressed when an assessment has been conducted to gauge whether students have learnt or not, the extent to which they have understood, and hence highlight the issues that need adjustment to improve learning and teaching. Besides providing feedback to students and teachers, assessment results can also give feedback to the administration for any necessary institutional measures that might be needed to improve learning, teaching and assessment processes.

While feedback focuses on current performance, and in most cases may simply justify the grade awarded, feed forward looks ahead to the next 
activities, offering constructive guidance on how to do better in future activities. A combination of feedback and feed forward ensures that assessment has an effective developmental impact on learning. Students need to be provided with the opportunity and facilitation to develop their own evaluative skills in order to use the feedback effectively. An effective feedback must explicitly address future activity; that is, feed forward. The three main roles of assessment are certainly interconnected and differentiating between teaching and assessment is both unnecessary and counterproductive.

\subsection{Alterative Assessment Practices}

Three teacher educators admitted that they try to use alternative assessments from time to time. Those hesitant to try alternative assessments commented that traditional tools, in particular formal tests and examinations, are quite useful because they are objective and impartial. This might look a plausible comment, as Wiggins (1993) affirms that alternative assessments are normally subjective and value-laden. In spite of such and other shortfalls, alternative assessments are believed to provide students with a wide range of tasks that reflect priorities and challenges found in the instructional activities that allow knowledge construction (Wiggins, 1993). One teacher educator raised a financial concern.

I change the type of assessment activities from time to time. I don't change the course content rather the assessment activities. When you practise alternative activities (innovations) that don't require money from the institution you'll normally be supported....The trouble arises when you attach your plans with some financial request. (Transcript T2, June 17, 2015)

While one teacher educator said she practises alternative assessments by trying to keep the course outline as conventional as possible, the other two provided a similar narration but by emphasising the fact that teachers have a high level of autonomy in the classroom.

As teachers, we have got the autonomy. The institution has provided guidelines on assessment such as using tests and examination. However, the teacher has the power to do whatever he/she believes to be useful for the students. No one will query if you fulfil all the basic activities as stipulated in the guidelines. The institutions do not deny teacher's creativity. (Transcript T4, June 19, 2015)

Therefore by recognizing the autonomy they have and being aware that institutions do not thwart teachers' creativity, effective teachers tend to constantly practise alternative assessment activities in their classes. The foregoing narrations contrast themselves sharply with one teacher educator, who thought that teachers need to inform the institutional administration 
whenever they plan to implement an alternative assessment activity in their class.

An important point one can learn from these narrations is that there may be a greater possibility of being at risk by implementing anything unconventional in the class. However, teachers may need to recognize the degree of autonomy they have in the class and the fact that institutions, in most cases, expect innovative performance of them. Teacher educators have, therefore, two main options: being conventional so that they remain safe, but at the cost of students learning very little; or being unconventional and subject to risk, but whose value is that of students learning critically and meaningfully.

\subsection{Integration of Teaching, Learning and Assessment}

When teachers carefully plan for classroom teaching and assessment of their students, teaching and assessment methods are expected to be compatible in the sense that they both focus on facilitating and improving student learning. Under such circumstances the three core classroom processes, teaching, learning and assessment, become properly connected. In response to the question on the assessment methods and tools they use, all eight teacher educators could not make any distinction between a method and a tool. By definition, an assessment method refers to a philosophical or pedagogical approach to assessing. This can be termed as the system through which assessment is carried out, an example of which is written assessment or practical assessment, formative or summative assessment. Assessment tools, on the other hand, Dunn (2011) describes as specific mechanisms that can be used for different assessment, with an example being exams, interviews, essays, posters, multiple choice questions, portfolios, online tests, videos and checklists, which can be used across a number of assessment methods. Also, the tools used to mark assessments, such as rubrics, can be considered assessment tools.

The list of assessment tools mentioned by teacher educators, in order of their importance is: tests; assignments; quizzes; seminar presentations; projects; oral questions; and micro teaching. One of them who has been in this field for about five years declared his preference on seminar presentations over other tools that he uses. He justified that seminar presentations offer the possibility of assessing multiple attributes of a student at the same time.

Seminar presentations is the most effective assessment tool because, through it I can assess several attributes such as organization of presentation, speech or talking, (that is oral presentation), defending skills, skills to handle questions, authenticity of responses, and skills to write reports. (Transcript T4, June 19, 2015)

Besides report writing skills, during seminar presentations he felt he could assess: written presentation, oral presentation, defending, questioning and 
question handling skills; organization; and authenticity of responses. The same assessment tool is highly preferred by the most experienced teacher educator (40 years of teaching). However, he has a different reason for liking it over others. This one believes that seminar questions keep students awake because each student must answer in writing the prepared seminar questions. During class, a few students are randomly pointed at to make their presentations based on what they prepared from the seminar questions. In this way, it is very likely that all students might work hard.

Only one teacher educator mentioned the use of microteaching for assessment. Microteaching is organized practice teaching. It aims to give student teachers confidence, support and feedback by letting them try out teaching among colleagues. For best results they can videotape themselves for individual review alongside an experienced teacher. This is done for year one students before they go on to their first teaching practice. This brings to mind the fact that there is also teaching practice as an assessment tool, which none of the teacher educators mentioned.

Teacher educators need to opt for methods that have a likelihood of embedding teaching, learning and assessment together. When a student is required to produce a reflection paper at the end of the week, for instance, there is no way she/he can avoid being attentive to actively engage in each class activity as the reflection will need to be an aggregate of the weekly teaching and learning activities. The traditional tools that most teacher educators use by no means detach assessment from teaching and learning activities. Conceived that way, assessment is planned and conducted as an afterthought when teaching is completed (see Figure 2). What was observed from such teachers is the fact that assessment is usually planned for at the end of teaching and learning, and worse still assessment results neither explicitly inform teaching nor provide effective feedback for improving learning. The dashed arrows in Fig. 2 emphasise the weak relationship of the elements and absence of effective feedback.

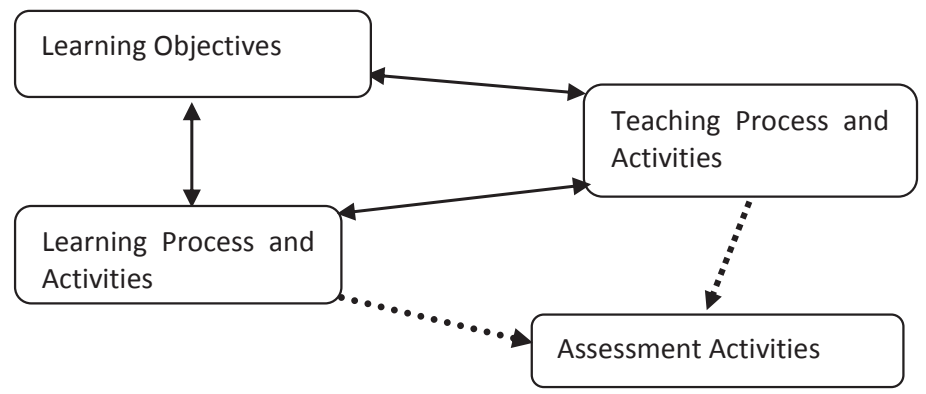

Figure 2. Traditional alignment of teaching, learning and assessment 


\section{$5 \quad$ Discussion of Findings and Implications}

Assessment defines what students regard as important, how they spend their time and how they come to see themselves as students and then as graduates. [Therefore], if you want to change student learning then change the methods of assessment. (Brown, 1997, p. 7).

Similar to Brown (1997), Gibbs (1992) asserts that assessment systems dominate what students are oriented toward in their learning. Both Brown and Gibbs further claim that even when teachers say they want students to be creative and critical thinkers, students often recognize that what is actually necessary is to memorize. This study found out that in most cases teachers are aware of the influence that assessment methods and practices have on student learning behaviour. At least they certainly know that if an assignment will not be marked and graded then many students will either not do it at all or passively respond to it. But how far have studies about assessment practically informed and reformed assessment practices?

\subsection{Active Learning in the Classroom}

The differences between learning as an active process and learning as a product conceptions recommend different roles for teachers and students in the classroom. The practical implications of this on assessment practices are diverse. In the first place, we need to make sure as much as possible that students' workloads are realistic, class contact hours are not too high, the amount of course material is manageable and that the assessment system is unthreatening. The latter can be achieved by, among others, continuous assessment instead of the current popular assessments that come at the end of semesters or programmes. Within continuous assessment there should be adequate formative feedback at regular intervals. Together with that, all assessments need to have clear criteria that are known by students before they perform the activity. Other assessment procedures and processes should be explicit, valid and reliable. As much as possible, assessment activities should be juxtaposed with the real-world tasks.

\subsection{Effective Teaching and Assessment}

It is essential to assess what students have achieved, but of critical relevance is to assess how they are learning. The emphasis on assessment for learning offers better prospects of improving a student's overall achievement. Thus, assessment for learning deals with assessment of learning as well. 
This study discovered that there are many factors that influence teachers' effectiveness in teaching and assessment. Generally, the factors are put into two main categories: teachers' trained attributes, or extrinsic characteristics, and situational factors. Teachers' extrinsic characteristics include: teachers' academic qualifications and educational background; their field of specialization or area of expertise; and their knowledge and skills. Situational factors involve: institutional policies; culture and practices; teaching and learning resources; teachers' social welfare; class sizes; and student-teacher interactions. However, the model established by this study (Fig. 3) further suggests that under normal circumstances, both teachers' extrinsic characteristics and situational factors can be mediated by teachers' intrinsic characteristics (dispositional factors), which include their personal interests, adaptability, perceptions, attitudes and beliefs which are usually not easily acquired through training or teaching. Although intrinsic characteristics can be manipulated, in most cases they are determinants of teachers' decisions to conduct teaching and assessment in certain ways.

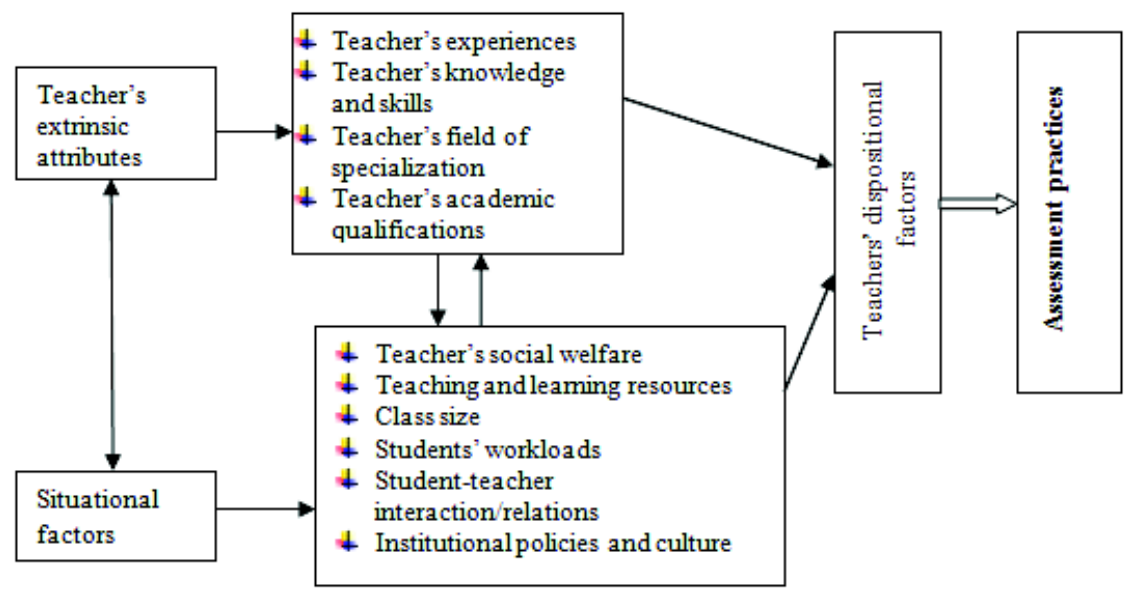

Figure 3: Model for factors affecting teaching and assessment effectiveness

On the other level, teachers' extrinsic attributes and situational factors are more likely to influence each other. In other words, situational factors can act as barriers to a teacher's effective practice of his/her role in the classroom. Overcoming such barriers will mostly depend on many factors, such as teachers' levels of awareness, personal skills and flexibility to deal with changes. 


\subsection{A Model for Integrating Teaching, Learning and Assessment}

In many instances, as supported by findings from this study, class activities miss a meaningful connection between teaching, learning and assessment. The fundamental principle of constructive integration of classroom activities is that an effective teaching system integrates teaching methods and assessment with the learning activities stated in the lesson objectives. All aspects of this system have to be in harmony in facilitating student learning (Biggs, 2003). The main reasons for integrating teaching, learning and assessment are: First, integration increases the probability that we will provide students with opportunities to learn and practise their knowledge and skills in meaningful ways. Second, when assessments and learning objectives are integrated then student grades are more likely to translate into learning. When learning objectives and assessments are misaligned, many students will focus their efforts on activities that will lead to good grades on assessments rather than focusing their efforts on learning what we believe is significant. The relationships of these variables (teaching, learning and assessment) largely depend not only on the teacher's knowledge, skills and values, but equally greatly on many other factors as observed in the preceding model (Fig. 3).

Likewise, Figure 4 portrays a model developed by this study in an endeavour to underline the critical need for teachers and educational institutions to consider the mutuality of teaching, learning and assessment more practically. This ideal integration (Fig. 4) is an alternative alignment that criticizes the traditional alignment (see Fig. 2). Separating assessment from teaching was clearly revealed to be the practice of many teacher educators.

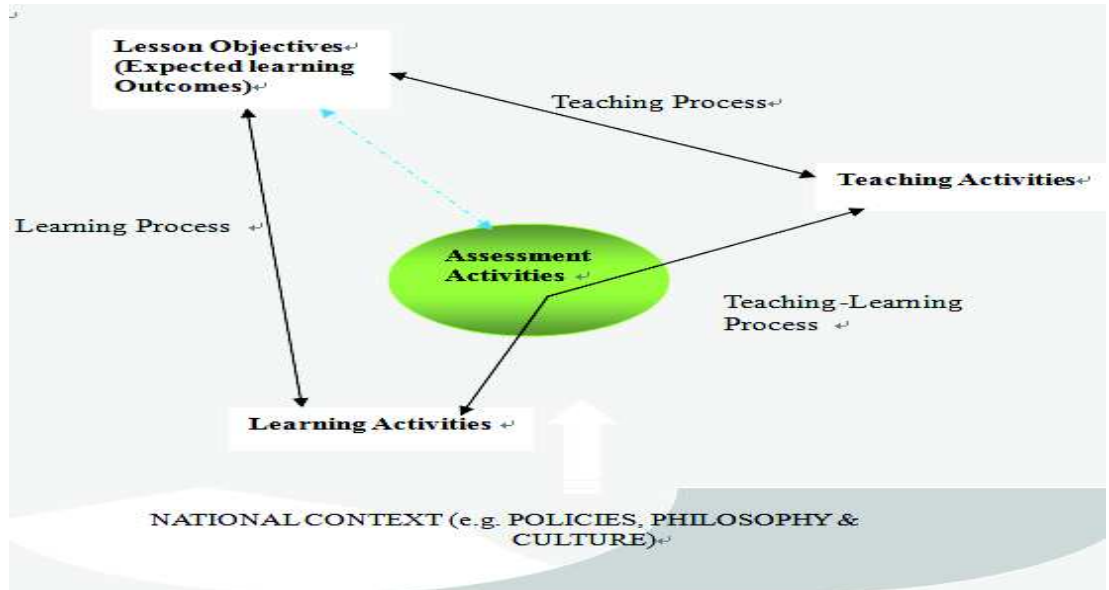

Figure 4: Model for integration of teaching, learning and assessment in the classroom 


\section{Conclusion}

It is disclosed that teacher educators are caught in a dilemma of either facilitating students' meaningful learning or preparing students who can earn high grades. Although learning and assessment are supposed to be two mutually dependent processes, in most teachers' perspectives they are treated as two separate entities. While assessment, just like learning, ought to be a transparent and shared activity between the teacher and students, it is usually handled under strict and confidential settings. Many teachers do erroneously believe that they must keep their assessments secret. The appalling side of this is that students view success as depending on how well they can guess what their teachers will ask on tests, examinations and other assignments. Very regrettably, some teachers even take pride in their ability to baffle students. For some reasons, such teachers may ask questions about disconnected concepts or vague understanding.

Assessments ought to reflect on the concepts and issues that are outlined in the learning objectives and emphasized during teaching and learning activities. This goes along with explicit assessment criteria that sometimes can be agreed upon by the teacher and students. Students need to see assessment as an essential measure of how learning objectives are being accomplished and how they can move forward as improving learners after receiving feedback from their teacher (Stiggins, 2007). Treating assessment as evaluation is criticised because that is equivalent to "teaching to the test or examination," in which the assessment activities become the key determinant of what teachers plan to teach and how they teach it. In an ideal situation, learning objectives should be a guide to what and how to teach, such that assessment of student learning becomes an expansion of those same objectives. Thus, teachers are "testing what they teach." If an idea is significant enough to assess, then it has to be equally significant enough to teach and learn.

\section{References}

Bennel, P. \& Mukyanuzi, F. (2005). Is there a teacher motivation crisis in Tanzania? Unpublished Research Report. Centre for International Education, Sussex University.

Biggs, J. B. (2003). Teaching for quality learning at university. Buckingham: The Open University Press.

Bruner, J. (1986). Actual minds, possible worlds. Cambridge, MA: Harvard University Press. 
Chung, M. A. (1997). Individual and small group interactions in learning to teach with a hypermedia case. Unpublished doctoral thesis, Purdue University.

Creswell, J.W. (2009). Research design: Qualitative, quantitative, and mixed methods approaches (3rd Ed.). Thousand Oaks, California: Sage Publications Ltd.

Darling-Hammond, L., \& Snyder, J. (2000). Authentic Assessment of teaching in context. Teaching and teacher Education, 16, 523-545.

Dunn, L. (2011). Selecting methods of assessment. Oxford, UK: Oxford Brookes University. Retrieved from http://www.brookes.ac.uk/services/ocsld/resources/methods.html.

Gibbs, G. \& Simpson, C. (2004). Conditions under which assessment supports students learning. Learning and Teaching in Higher Education. 1, 3-31.

Griffin, A., \& Hett, A. (2004). Performance-based pedagogy assessment of teacher candidates. Washington: Office of Superintendent of Public Instruction.

Huba, M. E., \& Freed, J. E. (2000). Learner-cantered assessment on college campuses-shifting the focus from teaching to learning. Boston, M.A: Alyn and Bacon.

Jidamva, G. (2012). Understanding and improving the quality of secondary school education: conceptions among teachers in Tanzania. Unpublished PhD. dissertation, Åbo Akademi, Finland.

Kajoro, P., Chirure, H. N. \& Simiyu, I. (2013). Educational Exigencies of the 21st Century: Implications for Teacher Education Programs in East Africa. Journal of Teaching and Learning, 9 (1). Retrieved from http://ojs.uwindsor.ca/.

King, N.A.S. (2013). Investigation of factors hindering quality education in secondary schools in Mbeya, Tanzania. International Journal of Learning and Development. 3 (6), 52-63.

Kitta, S. \& Fussy, D. (2013). Bottlenecks in preparation of quality teachers in Tanzania. Time Journals of Arts and Educational Research, 1(5), 29-38.

Miles, M., \& Huberman, A. M. (1994). Qualitative data analysis: An expanded sourcebook (2nd Ed.). Thousand Oaks, California: Sage Publications.

Ministry of Education and Vocational Training (MOEVT) (2007). Medium term strategic plan, 2007/08-2009/10. Dar es Salaam.

Mosha, H. J. (2004). New directions in teacher education for quality improvement in Africa. Papers in Education and Development, 24, 45-68.

Msonde, C. E. (2011). Enhancing teachers' competencies on learner-centred approaches through learning study in Tanzanian schools. Unpublished doctoral thesis, University of Hong Kong. Hong Kong. 
Mtitu, E. A. (2014). Learner-centred teaching in Tanzania: Geography teachers' perceptions and experiences. Unpublished doctoral thesis, Victoria University of Wellington. Wellington, Australia.

Mueller, J. (2005). The authentic assessment toolbox: Enhancing student learning through online faculty development. Journal of Online Learning and Teaching, 1 (1).

Najjumba, I. M. \& Marshall, J. H. (2013). Improving Learning in Uganda Vol. II: Problematic Curriculum Areas and Teacher Effectiveness: Insights from National Assessments. Washington, DC: World Bank. Doi: 10.1596/978-08213-9850-0.

Nzilano, J. L. (2013). Pre-service teachers' teaching competencies: The experience of practising teaching in secondary schools and teacher colleges. African Journal of Teacher Education, 3 (1). Retrieved https://journal.lib.uoguelph.ca/index.php/ajote/issue/view/157.

Omari, I. M. (2011).Concepts and techniques in educational assessments and evaluation, volume I. Dar es Salaam: Oxford University Press.

Onwuegbuzie, A. J., \& Collins, K. M. T. (2007). A typology of mixed methods sampling designs in social science research. The Qualitative Report, 12(2), 281-316.

Otaala, J., Maani, J. S. \& Bakaira, G. G. (2013). Effectiveness of University Teacher Education Curriculum on the Secondary School Teacher Performance in Uganda. CICE Hiroshima University, Journal of International Cooperation in Education, 15 (3), 95-112.

Puspitasari, K.A. (2008). Student assessment in distance education. PANdora distance education guidebook (1st ed.) Universitas Terbuka, Indonesia. Retrieved from www.pandora-asia.org.

Remesal, A. (2011). Primary and secondary teachers' conceptions of assessment: A qualitative study. Teaching and Teacher Education, 27 (2011), 472-482.

Rugonzibwa, P. (2014, January 13). Tanzania: New teacher training standards set. Tanzania Daily News. Retrieved from http://allafrica.com/stories/201401130018.html.

Schönfelder, W. (2011). CAQDAS and Qualitative syllogism logic-NVivo 8 and MAXQDA 10 compared. Forum: Qualitative Social Research, (12), 1.

Sewell, J. P., Frith, K. H. \& Colvin, M. M. (2010). Online assessment strategies: A primer. Journal of Online Learning and Teaching, Vol.6, No.1.

Shepard, L. A. (2000). The role of assessment in a learning culture. Educational Researcher, 29(7), 4-14.

Simonson, M, Smaldino, S. \& Albright, M. (2006). Teaching and learning at a distance- foundations of distance education. New Jersey: Pearson Prentice Hall. 
Stiggins, R. (2007). Assessments through the student's eyes. Educational Leadership, 64(8), 22-26.

Thomas, M. (2012). Teachers' beliefs about classroom assessment and their selection of classroom assessment strategies. Journal of Research and Reflections in Education, 6 (2), 103-112.

Unwin, C. G. \& Caraher, J. (2000). The heart of authenticity: Shared assessment in the teacher education classroom. Teacher Education Quarterly, Summer 2000.

Vygotsky, L. S. (1987). The Collected Works of L. S. Vygotsky (Vol. 1). In R. W. Rieber and A. S. Carton (Eds), Plenum Press, New York and London.

Wagner, T. (2010). The global achievement gap. New York: Basic Books.

Wiggins, G. P. (1993). Assessing student performance: Exploring the purpose and limits of testing. San Francisco: Jossey-Bass. 